\title{
Variation in Airborne Particulate Levels at a Newly Opened Underground Railway Station
}

\author{
Yingying Cha ${ }^{1 *}$, Minghui Tu ${ }^{1}$, Max EImgren ${ }^{2}$, Sanna Silvergren $^{2}$, Ulf Olofsson ${ }^{1}$ \\ ${ }^{1}$ Department of Machine Design, KTH Royal Institute of Technology, Stockholm, Sweden \\ ${ }^{2}$ SLB-analys, Environment and Health Administration, Stockholm, Sweden
}

\begin{abstract}
The construction of a new railway tunnel for commuter trains in Stockholm was completed in 2017. It included two modern stations (Odenplan and Stockholm City) with platform screen doors (PSD) and one old station (Stockholm Södra) without PSDs. This study evaluates the concentrations of airborne particulates at the new Odenplan station, focusing on the effects of traffic operation, system age and train movement. For comparison, the other two stations in the tunnel and an above-ground railway station (Solna) were also investigated. The new platform was clean prior to opening for traffic (the average concentration of $\mathrm{PM}_{10}$ and $\mathrm{PM}_{2.5}$ was 12 and $2 \mu \mathrm{g} \mathrm{m}{ }^{-3}$, respectively). Substantial increases in the $\mathrm{PM}_{10}$ and $\mathrm{PM}_{2.5}$ levels were observed after it came into service, with the average concentrations increasing to 120 and $30 \mu \mathrm{g} \mathrm{m} \mathrm{m}^{-3}$ after 1 week and then to 175 and $35 \mu \mathrm{g} \mathrm{m}^{-3}$ after 3 months of operation. The train movement factor (traffic frequency and train stopping period) was found to have a strong effect on the coarse-sized particle concentrations $(0.3-10 \mu \mathrm{m})$. Comparable levels of $\mathrm{PM}_{10}$ and $\mathrm{PM}_{2.5}$ were measured at both the new Odenplan station and the old station, where the amount of traffic was similar. For the other new station, Stockholm City, where traffic was only half as frequent, the $\mathrm{PM}_{10}$ and $\mathrm{PM}_{2.5}$ levels were substantially lower.
\end{abstract}

Keywords: Platform air quality; Railway tunnel; New railway station; Particulate matter; Platform screen door.

\section{INTRODUCTION}

Public transport by trains in tunnels has been increasing worldwide and plays a key role in rapid transit for high daily capacity. However, high concentrations of airborne particles have been reported on subway platforms, particularly in tunnels and underground stations in daily use (Johansson and Johansson, 2003; Seaton et al., 2005; Branı̌, 2006; Salma et al., 2007; Cheng et al., 2008; Kang et al., 2008; Kim et al., 2008; Kim et al., 2012; Mugica-Álvarez et al., 2012; Querol et al., 2012; Cartenì et al., 2015). These high particle concentrations can be attributed to various sources, including particles from ambient traffic-related pollutants (Branǐ, 2006; Cheng et al., 2008), mechanical wear particles from train components, and dust suspended by the movement of trains or passengers (Cartenì et al., 2015; Gustafsson et al., 2016; Cha et al., 2018).

The particle levels on railway platforms have been found to be strongly traffic-related. A study of European subway systems (Martins et al., 2016) found that the $\mathrm{PM}_{2.5}$ levels (mass concentration of the particles with aerodynamic

\footnotetext{
${ }^{*}$ Corresponding author.

E-mail address: yingcha@kth.se
}

diameters smaller than $2.5 \mu \mathrm{m}$ ) increased markedly in the morning and evening rush hours. A continuous decrease was observed during the night when the transport service was interrupted. Railroad tunnel measurements in Stockholm (Gustafsson et al., 2016) identified a pattern related to train frequency in the diurnal variation of $\mathrm{PM}_{10}$ (mass concentration of the particles with aerodynamic diameters smaller than $10 \mu \mathrm{m}$ ), with the maximum concentration of $\mathrm{PM}_{10}$ generally related to morning and evening rush hours.

Although increasing attention is being paid to the air quality in railway tunnels, there are few effective control measures to reduce those pollutants. Those that have been adopted include equipping new stations with advanced ventilation systems and full length platform screen doors (PSDs) (Kim et al., 2012; Martins et al., 2015b; Moreno et al., 2017). The installation of PSDs in the Seoul metro system reduced the mean $\mathrm{PM}_{10}$ on a station by $16 \%$ and the $\mathrm{PM}_{2.5}$ by $12 \%$ (Kim et al., 2012). An even greater effect can be obtained if an advanced ventilation system is installed. It has been reported that when an old subway platform in Barcelona was updated with an advanced optimized ventilation system, the particulate concentrations (both $\mathrm{PM}_{10}$ and $\mathrm{PM}_{2.5}$ ) were estimated to have dropped up to sevenfold (Querol et al., 2012).

The objective of this study was to evaluate the platform particulate levels at the Odenplan station (a newly built 
underground railway station in Stockholm), which is equipped with advanced ventilation systems and PSDs. The investigation focused on the influence of traffic operation time and the train movement factor (opening of PSDs and traffic frequency) on particle levels. Measurement campaigns were carried out before and after the operational start of the station. In addition, three other platforms (one above-ground station, one new station with half the traffic frequency, and one old station with the same traffic frequency) were simultaneously monitored for comparative purposes.

\section{METHODOLOGY}

\section{Instrumentation}

Two kinds of optical instruments were used to measure fine and coarse particles. There were two Optical Particle Sizers (OPS; Model 3330, TSI) and four Lighthouse Handheld particle counters (hereafter referred to as "Lighthouse"; 3016-IAQ, Lighthouse Benelux). They enable the measurement of particles ranging in size from 0.3 to $10 \mu \mathrm{m}$ in optical diameter. The OPS counted particles in up to 16 separate channels with 1 -second time resolution, while the Lighthouse reported the results for $\mathrm{PM}_{10}$ and $\mathrm{PM}_{2.5}$ every 10 seconds. A particle density of $4 \mathrm{~g} \mathrm{~cm}^{-3}$ was used to convert the particle number concentration (PNC) to mass concentration $\left(\mathrm{PM}_{10}\right.$ and $\left.\mathrm{PM}_{2.5}\right)$ for both optical instruments. This value of the effective density was based on the calibration from the reference measurement, which will be presented in more detail in the data analysis section.

A Nanoscan SMPS Nanoparticle Sizer (shortened to "Nanoscan"; Model 3910, TSI) was used to measure ultrafine particle concentrations. Using scanning mobility technology, it enables the detection of nanometre particles between 10 and $420 \mathrm{~nm}$ in electrical mobility equivalent diameter $\left(d_{b}\right)$, with 13 size channels and a time resolution of 1 minute.

For comparison, two Mini-WRAS aerosol spectrometers (hereafter referred as "Mini-WRAS"; Model 1.371, Grimm) were used to monitor a wide size range covering ultrafine, fine, and coarse fractions at the same time with one instrument. The Mini-WRAS combines two technologies (an optical aerosol spectrometer and a stepping-modeoperated electrode with Faraday cup electrometer) in one device, and is thus able to measure particles between 10 and $200 \mathrm{~nm}$ electrical mobility diameter and between 0.2 and $35 \mu \mathrm{m}$ optical diameter. With this counter, particles are measured in up to 41 size channels (10 electrical and 31 optical) with a time resolution of 1 minute.

An Electrical Low Pressure Impactor Plus (ELPI+; Dekati) was used as an additional reference measurement in order to calibrate $\mathrm{PM}_{2.5}$ and $\mathrm{PM}_{10}$ values for the optical measurement. It measures particles between $6 \mathrm{~nm}$ and $10 \mu \mathrm{m}$ in aerodynamic diameter $\left(d_{a}\right)$ using a low pressure impactor and electrical detection with sensitive electrometers. The detected particles are classified according to aerodynamic diameter into 14 impactor stages. The time resolution was 1 second.

\section{Measurement Campaign}

\section{Description of the Platforms}

Continuous aerosol monitoring was performed on four station platforms in Stockholm. Two (Stockholm City and Odenplan) were newly constructed stations inside a new railway tunnel (Fig. 1); Stockholm Södra is an old station inside the same tunnel; and Solna is above ground level. The 6-kilometre tunnel was constructed to run commuter trains and was completed in 2017. It first opened for regular traffic on 10 July 2017. Stockholm City (shortened to "City" hereafter) and Odenplan are the first in Stockholm to be equipped with PSDs and also have advanced ventilation systems. The City station has two platforms: one (Östra platform) for southbound trains and the other (Västra platform) for northbound trains. Thus, the daily flux rates of passenger and train numbers at each platform are about half of those at the Odenplan and Södra stations. Only commuter trains operate at the new stations. Advanced ventilation systems were also installed at the Södra station. At that station high-speed trains pass without stopping on a rail track close to the track for commuter trains. Traffic at the Solna station is a mix of commuter trains, high-speed trains, locomotives, and Arlanda express trains. In general, only commuter trains stop there.

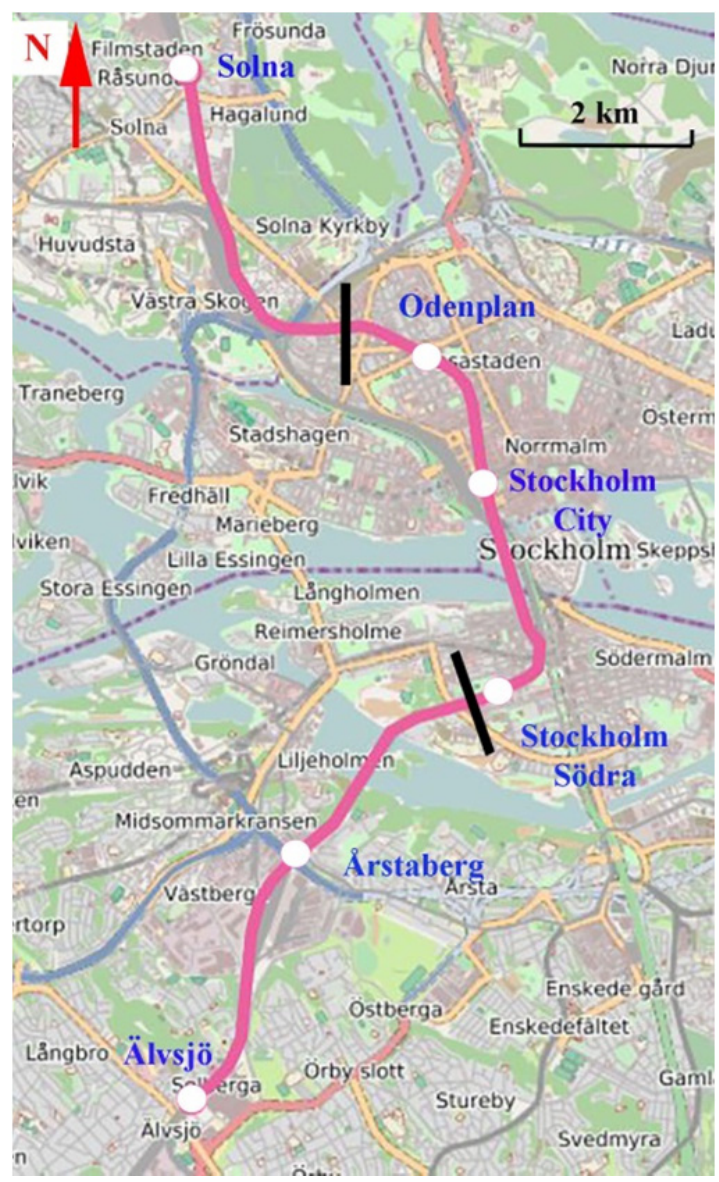

Fig. 1. Map of the measured stations along the railway route for commuter trains, in Stockholm, with the new tunnel marked between the two broad black lines. Three stations are inside the 6-kilometre long tunnel. 


\section{Measurements at the Odenplan Station}

In order to monitor air quality before and after the station was open for regular traffic, platform particle levels at the Odenplan station were investigated during the following three time periods:

- P1-before the station came into service for normal train operation on 21 June between 13:00 and 14:00 (no traffic, no passengers).

- $\quad$ P2 - after the station had been open for normal traffic for about a week. Measurements were taken between 20 July and 21 July (4-hour measurement per day: 08:00 09:00, 12:00-13:00, 16:00-17:00, and 18:00-19:00).

- P3 - after 3 months of normal operation. Measurements were taken between 30 October and 7 November (4 hours per day: 2 hours in the morning, 08:00 10:00, and 2 hours in the evening, 16:00-18:00).

One OPS was used for the measurement of PNC, $\mathrm{PM}_{10}$ and $\mathrm{PM}_{2.5}$ for all three periods. All the measurements were performed in the middle of the platform (Sampling Point 1, as shown in Fig. 2). In addition, a Lighthouse was used to simultaneously measure the platform $\mathrm{PM}_{10}$ and $\mathrm{PM}_{2.5}$ in $\mathrm{P} 3$. To evaluate the influence of train frequency on the particle levels, train stopping and starting times at the station were recorded during the measurement period.

In order to capture the influence of train movements clearly, an extra measurement was conducted close to the PSD (Sampling Point 2 in Fig. 2) with an OPS, a Nanoscan and a Lighthouse on 1 November 2017. Meanwhile, the mid-platform was monitored with the other OPS at Sampling Point 1 . Sampling Point 2 is about 0.5 metres away from the platform screen wall and 0.1 metres away from the opening of the PSD close to the service staff cabin.

\section{Parallel Measurements at Different Stations}

Parallel measurements were carried out at the Solna, Odenplan, City, and Södra stations on 6-7 November 2017. Each station was measured with a Lighthouse at the same time for 4 hours (08:00-10:00 and 16:00-18:00) on 6 November. In addition, the City and Södra stations were simultaneously measured with an OPS and a Mini-WRAS on 6 November. The Odenplan and Södra stations were measured at the same time with an OPS and a Mini-WRAS on 7 November. All of the instruments were placed in the middle of the measured platforms.

\section{Reference Measurement for Calibration}

A reference test was performed at the Södra station between 14:00 and 15:00 on 6 November. It used all the devices involved in this study: 4 Lighthouse counters, 2 OPS spectrometers, 2 Mini-WRAS devices, 1 Nanoscan, and 1 ELPI+.

\section{Data Analysis and Quality Control}

Statistical analysis was carried out to determine the correlations between 1-hour averaged $\mathrm{PM}_{10}$ and $\mathrm{PM}_{2.5}$ data (assuming a unit density of $1 \mathrm{~g} \mathrm{~cm}^{-3}$ ) from all OPS, MiniWRAS, and Lighthouse instruments for the reference measurement. For the $\mathrm{PM}_{10}$ result, strong correlations were shown between individual OPSs $\left(r^{2}=0.94\right)$, and individual Lighthouses $\left(r^{2}=0.97-0.99\right)$. Good agreement was observed between OPSs and Lighthouses $\left(r^{2}=0.86-0.93\right)$, and also between OPSs and Mini-WRASs $\left(r^{2}=0.74-0.84\right)$. Weaker correlations between Mini-WRASs and Lighthouses were observed $\left(r^{2}=0.61-0.75\right)$. Since good comparability was shown between OPS and Lighthouse, and between OPS and Mini-WRAS, one of the OPSs was chosen as a reference device and all of the measurement results from other instruments were calibrated to it using linear correlation analysis (the correlation result is shown in Table S1).

However, relying on unit density when calculating $\mathrm{PM}_{10}$ and $\mathrm{PM}_{2.5}$ results in underestimates owing to the amount of enrichment by metal elements in the railway particles. The hourly average $\mathrm{PM}_{10}$ given by the ELPI+ was about $183 \mu \mathrm{g} \mathrm{m}^{-3}$ at the Södra station, a level similar to previous measurements (around $150 \mu \mathrm{g} \mathrm{m}^{-3}$ ) performed at the same station (Stockholms läns landsting, 2015). As it was found that the $\mathrm{PM}_{10}$ of railway particles measured with the ELPI+ (assuming unit density) was in general agreement with the gravimetrically determined $\mathrm{PM}_{10}$ level from the TEOM at the Arlanda Central station in one of our previous field studies (Cha and Olofsson, 2018, under review for publication), we decided to use the $\mathrm{PM}_{10}$ from ELPI+ in this study as a reference value. A density factor $\left(4 \mathrm{~g} \mathrm{~cm}^{-3}\right)$ was determined by the ratio of $\mathrm{PM}_{10}$ measured with the ELPI+ to the average of the two OPS-measured total volume concentrations for the reference measurement. All of the

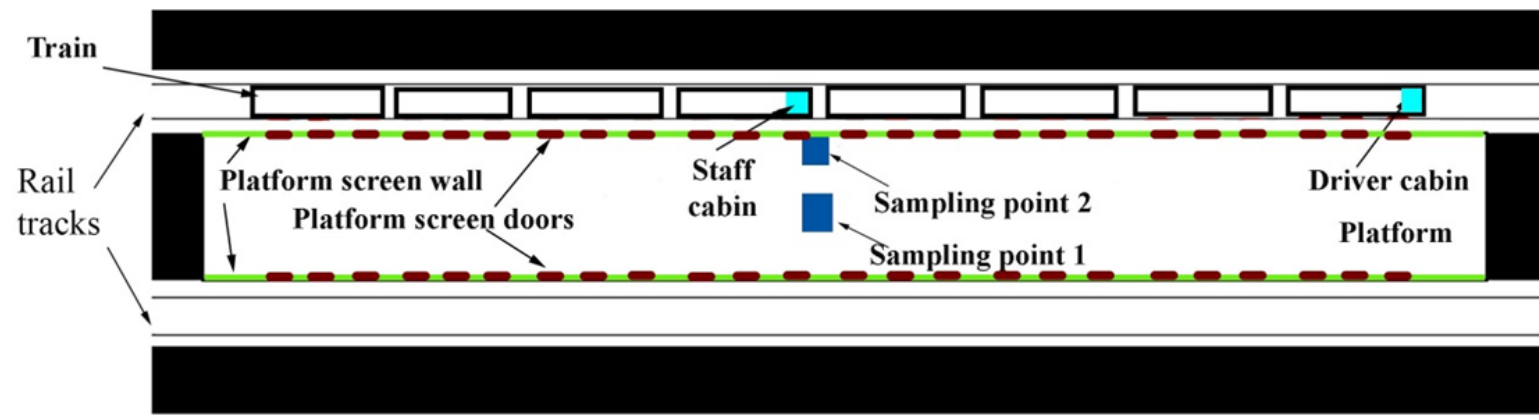

Fig. 2. Schematic diagram of Odenplan station platform with placement of measurement devices. The dimensions of the platform are about $260 \mathrm{~m}$ (length) $\times 220 \mathrm{~m}^{2}$ (cross section area). Sampling point 1 is in the middle of the platform, while sampling point 2 is about 0.5 meters away from the upper platform screen wall and 0.1 meters away from the opening of the PSD close to the service staff cabin. 
$\mathrm{PM}_{10}$ and $\mathrm{PM}_{2.5}$ levels reported in this study were first calibrated to the reference OPS as described above, and then recalculated by multiplying the factor obtained by the comparison between ELPI+ and OPS measurements. Note that this factor was used only for the recalculation of particle mass concentration measured in the tunnel environment. For the above-ground station, a particle density of $2.5 \mathrm{~g} \mathrm{~cm}^{-3}$ was used instead, which corresponds to outdoor road aerosol.

In addition to the calibration measures described above, all of the instruments were zero calibrated and time synchronized before the start of any particular experiment. Condition parameters (temperature and humidity) were measured for each test to ensure that the test condition was within the acceptable operating range for each device.

\section{RESULTS}

\section{Variability of $P M_{10}$ and $P M_{2.5}$ on the Odenplan Station}

Platform $\mathrm{PM}_{10}$ and $\mathrm{PM}_{2.5}$ levels at the Odenplan station (mid-platform at Sampling Point 1) were calculated for different time periods from the number concentrations measured with the OPS. A density of $4 \mathrm{~g} \mathrm{~cm}^{-3}$ was used for the PM calculations. The results are shown in Fig. 3. Period $1(\mathrm{P} 1)$ is the period when the station was closed to normal traffic (no traffic and passengers on 21 June). The test periods after the platform had been open to normal traffic for about 1 week and for about 3 months are labelled as P2 and P3, respectively. It can be seen that the station was clean with very low particle concentrations (about 12 and $2 \mu \mathrm{g} \mathrm{m}^{-3}$ for average $\mathrm{PM}_{10}$ and $\mathrm{PM}_{2.5}$ ) on 21 June. Noticeable increases in $\mathrm{PM}_{10}$ and $\mathrm{PM}_{2.5}$ levels were observed once the station came into service. Even more increases were noticed as the traffic service continued. After running for 1 week, the average $\mathrm{PM}_{10}$ and $\mathrm{PM}_{2.5}$ were 120 and $30 \mu \mathrm{g} \mathrm{m}^{-3}$. After 3 months, those levels increased to 175 and $35 \mu \mathrm{g} \mathrm{m}^{-3}$, representing about a 15 -fold and 18 -fold increase in $\mathrm{PM}_{10}$ and $\mathrm{PM}_{2.5}$ compared to the levels on 21 June.
Fig. 4 shows half-hourly averaged $\mathrm{PM}_{10}$ and $\mathrm{PM}_{2.5}$ values measured simultaneously with OPS and Lighthouse. Values from the Lighthouse measurement were calibrated to the reference OPS (as presented in the "Methodology" section). Similar levels were shown for Lighthouse and OPS measurements for the first 3 days. On 1 November, the Lighthouse results show the $\mathrm{PM}_{10}$ and $\mathrm{PM}_{2.5}$ measured close to the PSD (at Sampling Point 2), while the OPS values are for the measurement at the middle of the platform (Sampling Point 1). Both $\mathrm{PM}_{10}$ and $\mathrm{PM}_{2.5}$ levels were higher at door-side than the mid-platform, with even higher levels at door-side measured in the morning. Average particle levels in the morning and evening and the mean for the whole day are summarized in Table 1. It can be seen that all instruments give higher particle levels in the evening than in the morning, except on 1 November when the levels are similar for the morning and evening.

\section{Influence of Train Movement Factor (Frequency and Stopping Time)}

Fig. 5 shows the relationship between PM levels $\left(\mathrm{PM}_{10}\right.$ and $\mathrm{PM}_{2.5}$ ) and train frequency (number per half hour) at the Odenplan, Stockholm City and Stockholm Södra stations. An increasing trend can be observed for both $\mathrm{PM}_{10}$ and $\mathrm{PM}_{2.5}$ as train frequency increases. The City station has the lowest train frequency (5-9 trains per half hour) and the lowest particle concentrations. Note that the $\mathrm{PM}_{10}$ and $\mathrm{PM}_{2.5}$ levels corresponding to Train Number 9 at the City station were measured in the morning from 08:0008:30, after a long service interruption during the night. It is of interest that the Odenplan and Södra stations have comparable train frequency and comparable $\mathrm{PM}_{10}$ and $\mathrm{PM}_{2.5}$ levels, despite the former being a new station and the latter an old station.

The variations in $\mathrm{PM}_{10}, \mathrm{PM}_{2.5}$, and $\mathrm{PNC}$ were analysed to determine the influence of the PSD opening after southbound (from Solna to Älvsjö) trains stopped. Fig. 6 is

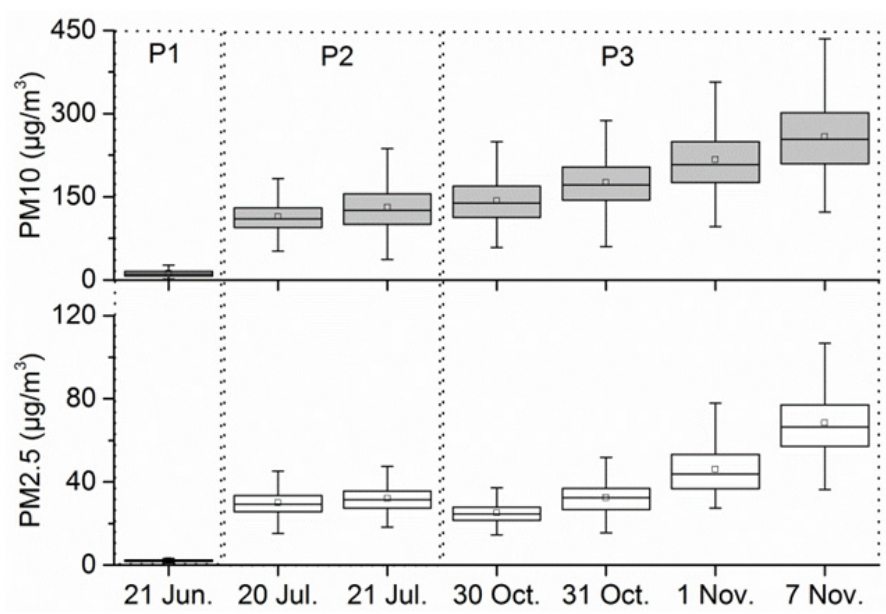

Fig. 3. Boxplot of $\mathrm{PM}_{10}$ and $\mathrm{PM}_{2.5}$ levels measured on Odenplan station (at measurement point 1) with OPS. P1 is the period before the station was open for traffic (no traffic and no passengers); P2 is after one week of operation; P3 is after traffic operation for three months. The box encloses values between the upper $25 \%$ and lower $25 \%$. The line and the square inside the boxes represent the median and the mean values, respectively. The whiskers show ranges between upper and lower $10 \%$ values. 


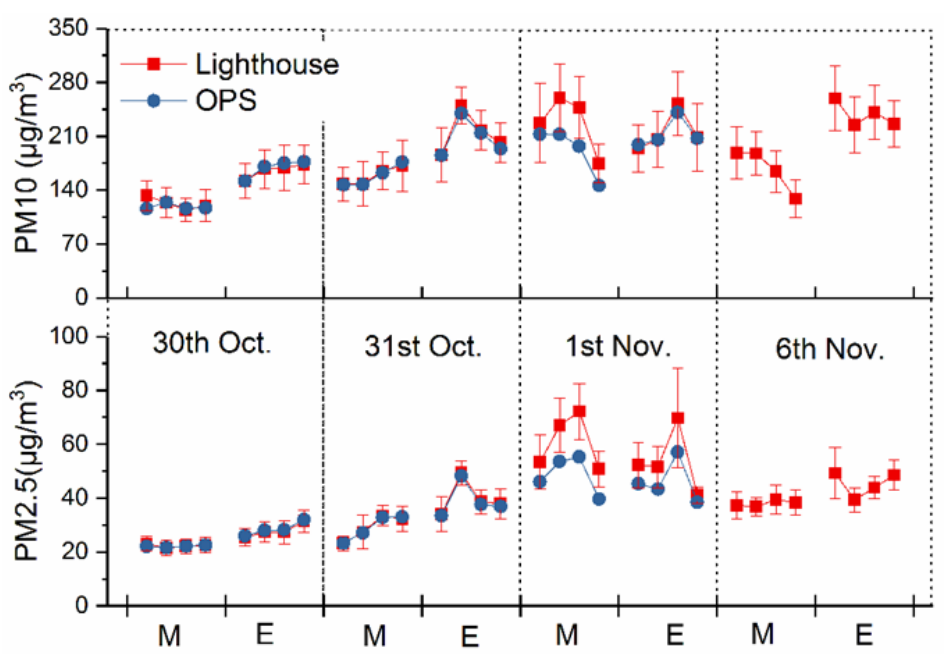

Fig. 4. Half-hourly averaged $\mathrm{PM}_{10}$ and $\mathrm{PM}_{2.5}$ measured with Lighthouse (red) and OPS (blue) at Odenplan station from 30 October to 6 November. M represents morning (08:00-10:00) measurements, and E represents evening (16:00-18:00). Standard deviations from Lighthouse measurements are shown as well for $\mathrm{PM}_{10}$ and $\mathrm{PM}_{2.5}$.

Table 1. Calibrated $\mathrm{PM}_{10}$ and $\mathrm{PM}_{2.5}$ measured simultaneously with different instruments on Odenplan station. All results are for the middle of the platform at measurement point 1, with an exceptional case measured with the L2 on 1 November for door-side at measurement point 2 .

\begin{tabular}{|c|c|c|c|c|c|c|c|}
\hline \multirow{2}{*}{ Date } & & \multicolumn{3}{|c|}{$\mathrm{PM}_{10}\left(\mu \mathrm{g} \mathrm{m}^{-3}\right)$} & \multicolumn{3}{|c|}{$\mathrm{PM}_{2.5}\left(\mu \mathrm{g} \mathrm{m}^{-3}\right)$} \\
\hline & & OPS & Lighthouse & Mini-WRAS & OPS & Lighthouse & Mini-WRAS \\
\hline \multirow[t]{3}{*}{30 Oct. } & morning & 118 & 121 & & 22 & 22 & \\
\hline & evening & 168 & 163 & & 28 & 28 & \\
\hline & Mean & 143 & 142 & & 25 & 25 & \\
\hline \multirow[t]{3}{*}{31 Oct. } & morning & 158 & 158 & & 29 & 29 & \\
\hline & evening & 201 & 205 & & 37 & 38 & \\
\hline & Mean & 180 & 182 & & 33 & 34 & \\
\hline \multirow[t]{3}{*}{1 Nov. } & morning & 192 & 223 & & 49 & 59 & \\
\hline & evening & 214 & 209 & & 46 & 54 & \\
\hline & Mean & 203 & 216 & & 47 & 56 & \\
\hline \multirow[t]{3}{*}{6 Nov. } & morning & & 167 & & & 36 & \\
\hline & evening & & 237 & & & 45 & \\
\hline & Mean & & 202 & & & 40 & \\
\hline \multirow[t]{3}{*}{7 Nov. } & morning & 215 & & 234 & 58 & & 40 \\
\hline & evening & 302 & & 309 & 79 & & 46 \\
\hline & Mean & 258 & & 272 & 68 & & 43 \\
\hline
\end{tabular}

an example for $\mathrm{PM}_{10}$ and $\mathrm{PM}_{2.5}$, while Fig. 7 shows PNC. Measurements conducted close to the PSDs show substantial increases in $\mathrm{PM}_{10}, \mathrm{PM}_{25}$ and $\mathrm{PNC}$ of particle sizes of $0.3-$ $10 \mu \mathrm{m}$ (detected with the OPS) when the doors open. However, the ultrafine fractions $(0.01-0.42 \mu \mathrm{m})$ measured with the Nanoscan did not show a similar increase during the door-opening period. Compared to the measurement at door-side, the influence of door opening was less significant on the $\mathrm{PM}_{10}$ and $\mathrm{PM}_{2.5}$ concentrations at the middle of the platform. There, a lower $\mathrm{PM}_{10}$ level was detected, while the $\mathrm{PM}_{2.5}$ showed a similar level to that measured at the door-side measurement point.

\section{Comparison between Different Stations}

Parallel measurements taken at the middle of the platforms with one Lighthouse at each of the stations (Solna, Odenplan,
City and Södra) are summarized by the calibrated $\mathrm{PM}_{10}$ and $\mathrm{PM}_{2.5}$ levels shown in Fig. 8. The calibration details are in the "Methodology" section. It can be seen that the average $\mathrm{PM}_{10}$ and $\mathrm{PM}_{2.5}$ values at the Odenplan station were similar to those measured at the Södra station, while the levels at the Odenplan station were much higher than those at the City station. They were even higher than those detected at the above-ground station (Solna).

Table 2 shows the measurements for those four stations with different instruments on 6-7 November. All the measurements were performed in the middle of the platform. The Lighthouse and OPS gave similar levels of $\mathrm{PM}_{10}$ and $\mathrm{PM}_{2.5}$ with small deviations, while the Mini-WRAS results were higher than those measured with the OPS and Lighthouse due to the wider size range covered by the Mini-WRAS. In general, the highest particle levels were 

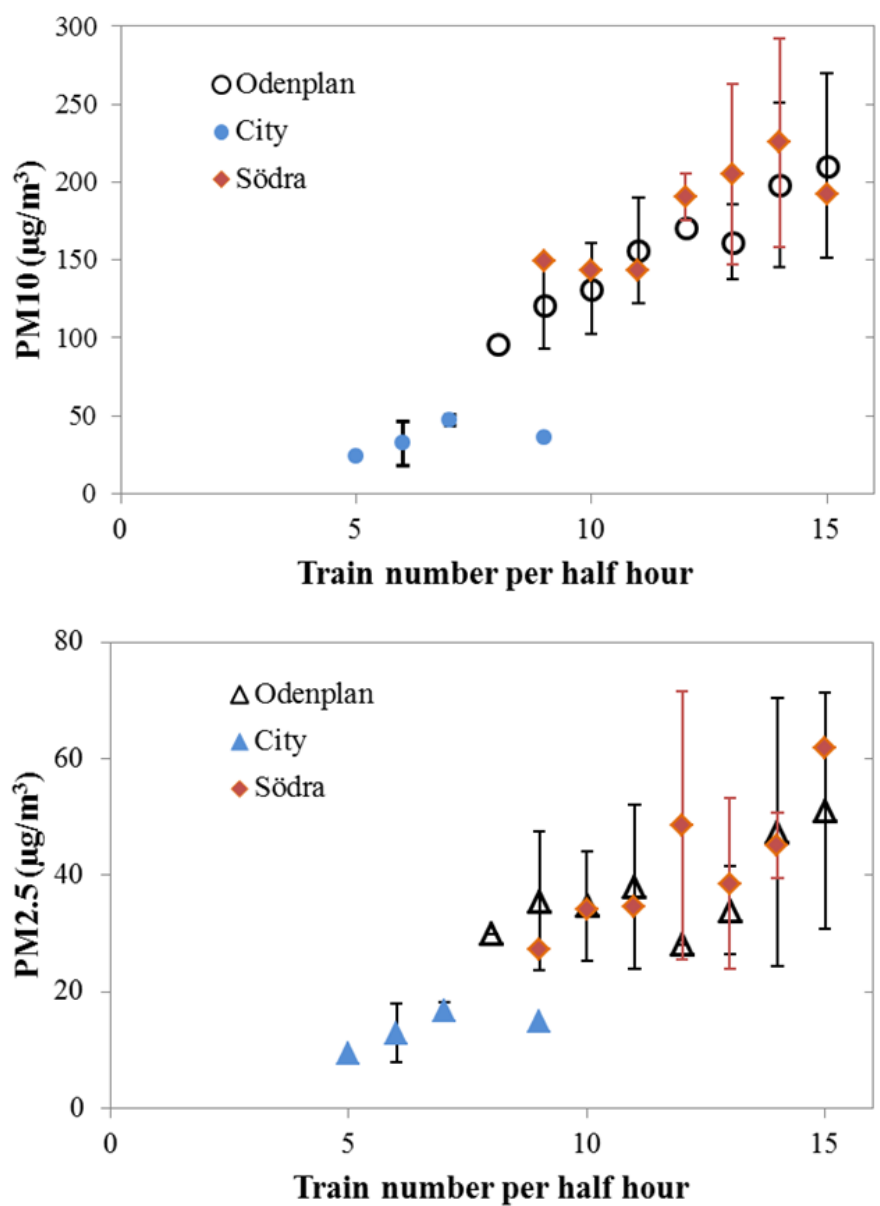

Fig. 5. Relationship between average mass concentrations $\left(\mathrm{PM}_{10}\right.$ upper panel and $\mathrm{PM}_{2.5}$ bottom panel) and train numbers per half hour at Odenplan, City and Södra stations, measured with OPS. The error bars show the standard deviations of the $\mathrm{PM}_{10}$ and $\mathrm{PM}_{2.5}$ at corresponding train numbers.

observed at the Södra station, followed by the Odenplan station with very similar levels. The least polluted station was the above-ground station. The particle concentrations showed higher levels in the evening than in the morning for all of those stations. An exceptional case occurred at the Södra station on 6 November when a diesel train passed by in the morning and produced a substantial increase in ultrafine particles as measured by the Mini-WRAS.

\section{Particle Size Distribution}

Fig. 9 shows the average particle number and mass size distribution measured simultaneously with the OPS and Grimm Mini-WRAS on 7 November 2017 at Odenplan. The OPS result generally agrees with the Mini-WRAS distribution in the size ranging between 0.3 and $10 \mu \mathrm{m}$, despite the fact that the OPS overestimated the number concentration of coarser particles compared to the MiniWRAS. The OPS result showed a weak bimodal (around 1 and $2 \mu \mathrm{m}$ ) size distribution. The Mini-WRAS measurement showed a nano-sized mode of around $70 \mathrm{~nm}$.

\section{DISCUSSION}

The variability of railway platform particulate levels is associated with various factors including the age of the railway station, the performance of the ventilation system, the train frequency, the number of commuters, the train operating conditions (e.g., type of brake, speed, and type of electric power supply system), and the season. The levels can even differ depending on the measurement methods. It has commonly been believed that the implementation of advanced ventilation systems and PSDs will contribute to reducing particle concentrations for newly designed platforms (Kim et al., 2012; Querol et al., 2012; Martins et al., 2015b; Moreno et al., 2017). However, our study found that the particle concentrations measured at one of the newly constructed stations (equipped with advanced ventilation systems and PSDs) were comparable with those at the old station. Looking at Fig. 8, a graphical ANOVA can be performed. Since the boxes of the box plots of Stockholm Södra and Stockholm Odenplan are not separated, there is no statistically significant difference at a $95 \%$ level. The $\mathrm{PM}_{10}$ and $\mathrm{PM}_{2.5}$ levels on the new platform are found to be strongly traffic-related and tend to increase during the day.

\section{Variation of $\mathrm{PM}_{10}$ and $\mathrm{PM}_{2.5}$ Levels}

Before the Odenplan station opened for service, it was clean, with low levels of $\mathrm{PM}_{10}$ and $\mathrm{PM}_{2.5}$ (12 and $2 \mu \mathrm{g} \mathrm{cm}{ }^{-3}$, 

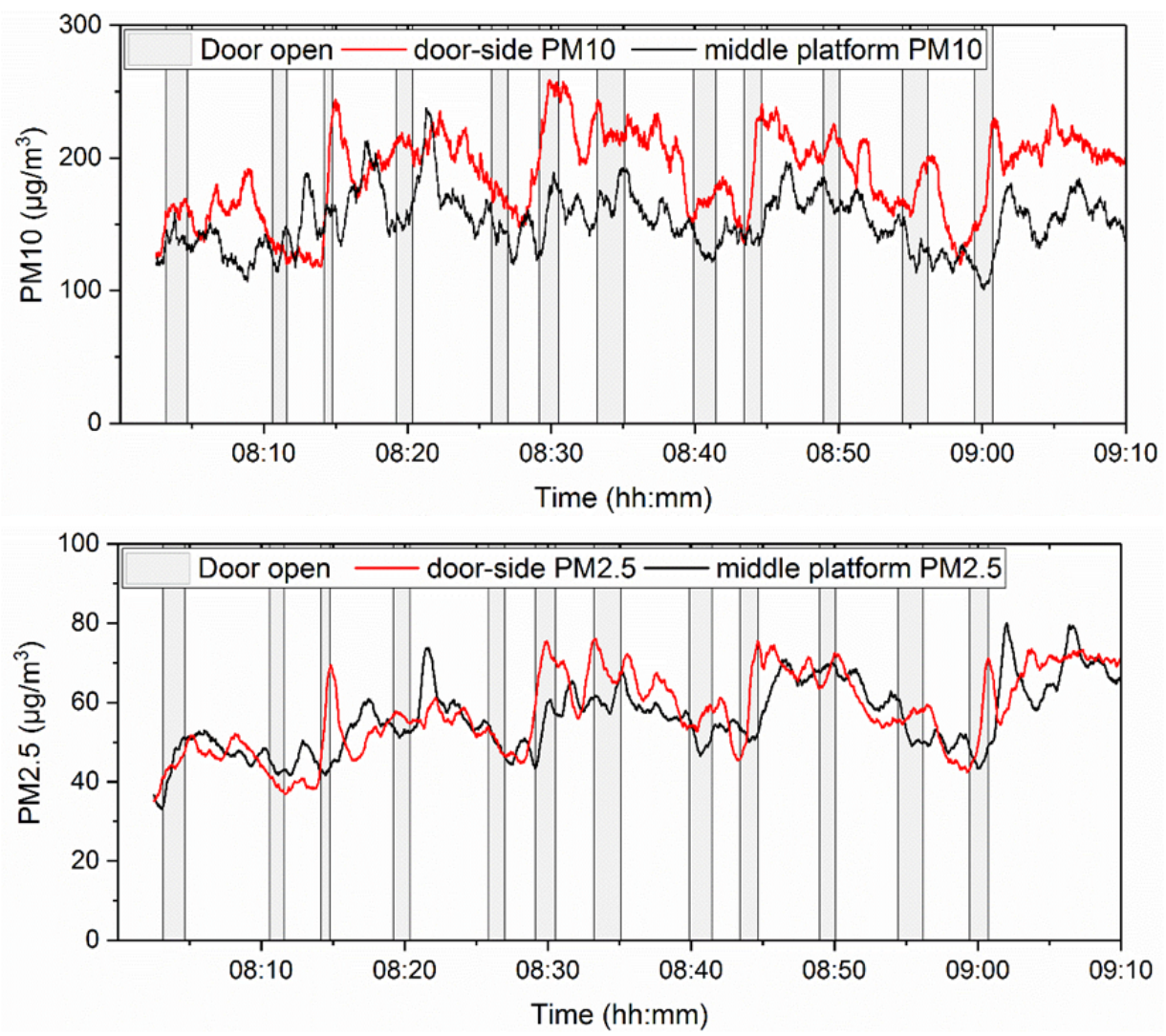

Fig. 6. Variation of $\mathrm{PM}_{10}$ (upper panel) and $\mathrm{PM}_{2.5}$ (bottom panel) levels measured with OPS at door-side (measurement point 2) and at mid-platform (measurement point 1) on Odenplan station on 1 November. The PSD opening periods when southbound trains stopped at the station are marked by grey bars.

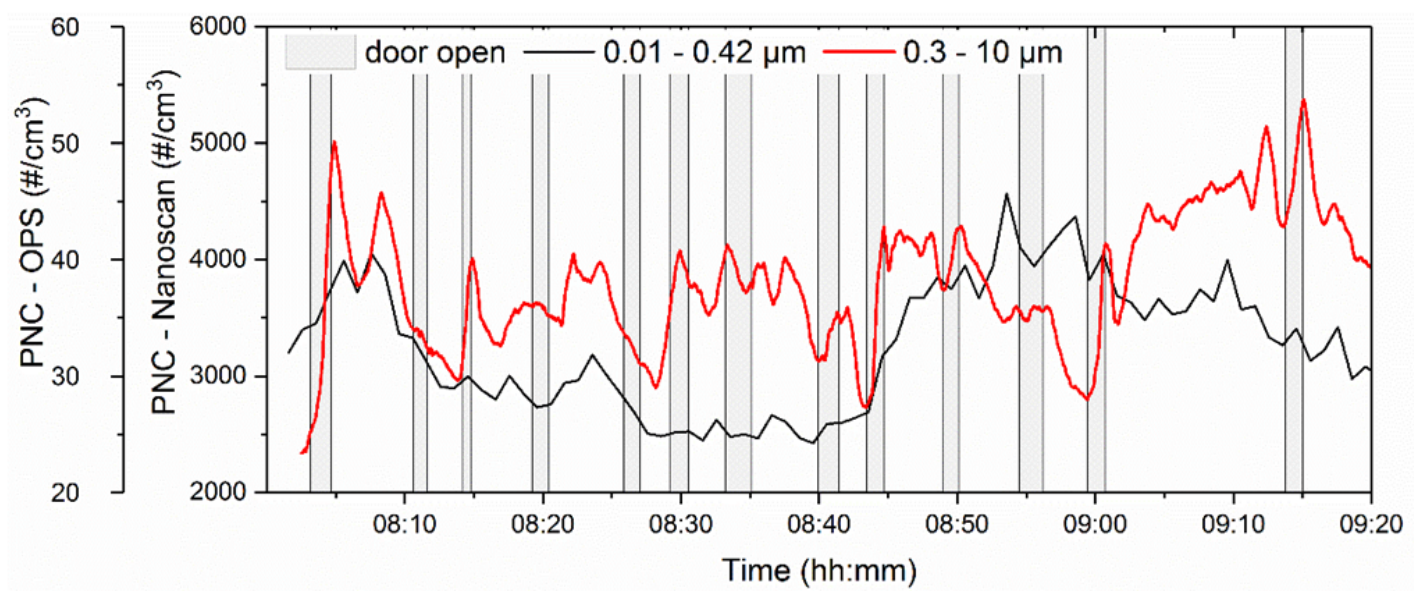

Fig. 7. Variation of the particle number concentration (for diameter sizes of $0.3-10 \mu \mathrm{m}$ from OPS measurement and 0.01$0.42 \mu \mathrm{m}$ from Nanoscan) measured at door-side, with the door open periods marked by grey bars when southbound trains stopped at Odenplan.

respectively). Data on urban background air quality provided by Stockholm Air Quality and Noise (SLB) show that the background particulate matter varied between 0.5 and $31 \mu \mathrm{g} \mathrm{m}^{-3}$ for $\mathrm{PM}_{10}$ and 0.4 and $27 \mu \mathrm{g} \mathrm{m}^{-3}$ for $\mathrm{PM}_{2.5}$ between 30 October and 7 November 2017. Compared to this background air, the $\mathrm{PM}_{10}$ in the tunnel was at a low level while the $\mathrm{PM}_{2.5}$ was even lower. Once the station opened to traffic, the platform air quality deteriorated with increasing concentrations of particles being monitored. The average after running for 1 week was $120 \mu \mathrm{g} \mathrm{m}^{-3}$ for $\mathrm{PM}_{10}$ and $30 \mu \mathrm{g} \mathrm{m}^{-3}$ for $\mathrm{PM}_{2.5}$. These increased to 175 and $35 \mu \mathrm{g} \mathrm{m}^{-3}$ after 3 months. The results from 7 February were excluded because possible combustion particles on that day could have affected the data. The $\mathrm{PM}_{10}$ and $\mathrm{PM}_{2.5}$ levels after 3 months' service represent a roughly 25 -fold and 7-fold increase over the initial environment. 

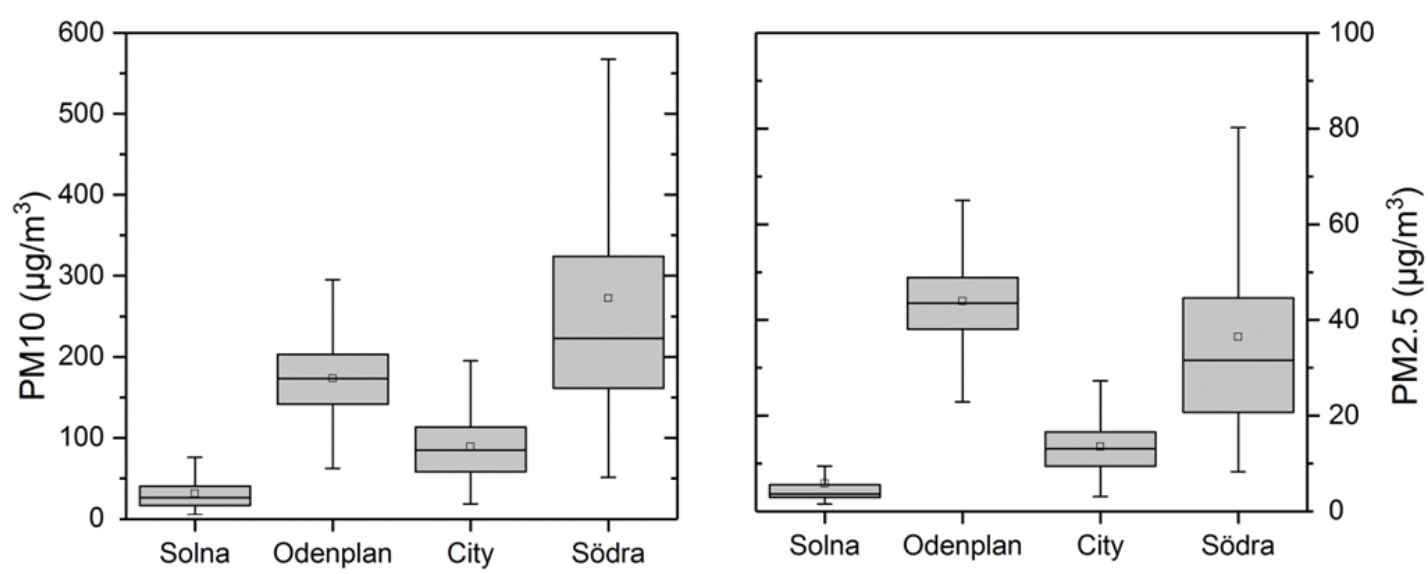

Fig. 8. Boxplot of $\mathrm{PM}_{10}$ (left panel) and $\mathrm{PM}_{2.5}$ (right panel) measured simultaneously at Solna (above-ground open station, assuming an effective density of $2.5 \mathrm{~g} \mathrm{~cm}^{-3}$ for converting optical number concentration to mass concentration), Odenplan, City, and Södra stations (all three stations are underground, assuming an effective density of $4 \mathrm{~g} \mathrm{~cm}^{-3}$ for the recalculation of $\mathrm{PM}_{10}$ and $\mathrm{PM}_{2.5}$ ). Measurements were made on 6 November.

Table 2. $\mathrm{PM}_{10}$ and $\mathrm{PM}_{2.5}$ levels measured at different stations (Solna, Odenplan, City, and Södra) in the middle of the platforms with three types of particle counters (OPS, Lighthouse, and Mini-WRAS). The calculation of the PM P $_{10}$ and $\mathrm{PM}_{2.5}$ at Solna station was based on an effective density of $2.5 \mathrm{~g} \mathrm{~cm}^{-3}$, while for the others it was based on an effective density of $4 \mathrm{~g} \mathrm{~cm}^{-3}$ ).

\begin{tabular}{|c|c|c|c|c|c|c|c|c|}
\hline \multirow{2}{*}{ Date } & \multirow{2}{*}{$\begin{array}{l}\text { Stations } \\
\text { Device }\end{array}$} & & \multicolumn{3}{|c|}{$\mathrm{PM}_{10}\left(\mu \mathrm{g} \mathrm{m}^{-3}\right)$} & \multicolumn{3}{|c|}{$\mathrm{PM}_{2.5}\left(\mu \mathrm{g} \mathrm{m}^{-3}\right)$} \\
\hline & & & OPS & Lighthouse & Mini-WRAS & OPS & Lighthouse & Mini-WRAS \\
\hline \multirow[t]{12}{*}{6 Nov. } & Solna & morning & & 27 & & & 5 & \\
\hline & & evening & & 62 & & & 10 & \\
\hline & & Mean & & 45 & & & 8 & \\
\hline & Odenplan & morning & & 167 & & & 36 & \\
\hline & & evening & & 237 & & & 45 & \\
\hline & & Mean & & 202 & & & 40 & \\
\hline & City & morning & 38 & 43 & 53 & 10 & 11 & 9 \\
\hline & & evening & 66 & 80 & 112 & 16 & 19 & 13 \\
\hline & & Mean & 52 & 62 & 83 & 13 & 15 & 11 \\
\hline & Södra & morning & 169 & 167 & 267 & 30 & 30 & 61 \\
\hline & & evening & 262 & 270 & 244 & 43 & 44 & 34 \\
\hline & & Mean & 215 & 219 & 255 & 37 & 37 & 48 \\
\hline \multirow[t]{6}{*}{7 Nov. } & Odenplan & morning & 215 & & 234 & 58 & & 40 \\
\hline & & evening & 302 & & 309 & 79 & & 46 \\
\hline & & Mean & 258 & & 272 & 68 & & 43 \\
\hline & Södra & morning & 225 & & 266 & 35 & & 44 \\
\hline & & evening & 279 & & 280 & 53 & & 46 \\
\hline & & Mean & 252 & & 273 & 44 & & 45 \\
\hline
\end{tabular}

Fig. 4 suggests that the platform particle concentration might be expected to reach its maximum level, although the level measured by the OPS increased still more on 7 February, as shown in Fig. 3. It should be noted that there was a large fire in the city that morning. Passengers passing the fire site might have brought along some combustion particles and thus increased the particle levels at the Odenplan station when they got off there. However, the measurement period is limited and further studies are needed to determine whether the platform particle concentration increases to an even higher level or whether it has reached its maximum value. It should also be noted that the newly installed rail profiles are still being run-in to adapt to the wheel profiles of the commuter trains that have been in service for several years. As the contact conditions between steel railway wheel and rail become more adapted to each other, it is likely that the wear will decrease together with the amount of airborne wear particles from the wheel-rail contact (Telliskivi and Olofsson, 2001; Sundh and Olofsson, 2011).

\section{Influence of Train Movement Factor}

As in previous studies (Gustafsson et al., 2016; Cha et al., 2018), we observed a strong relationship between train movements and particle concentrations. This finding enables us to interpret the sources contributing to the 


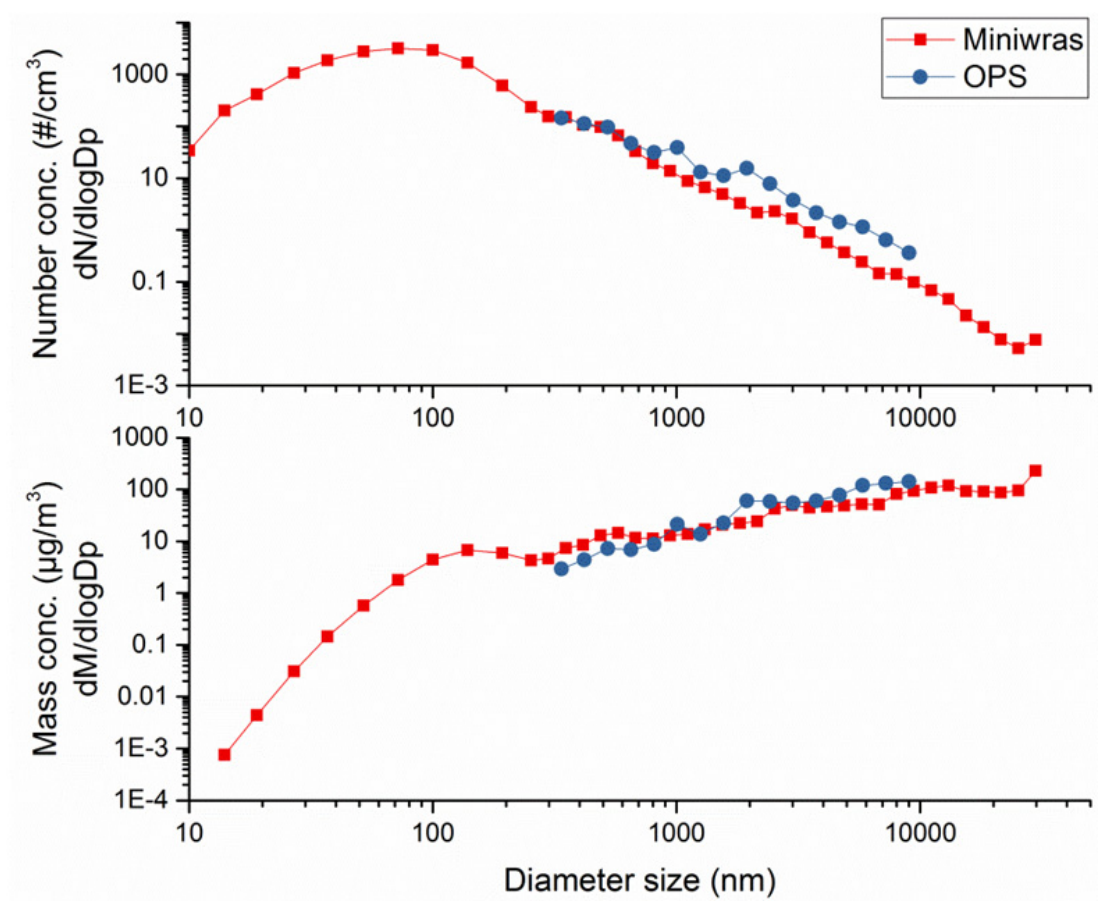

Fig. 9. Particle number size distribution (upper panel) and mass size distribution (bottom panel) for the average of the measurement in the evening at Odenplan station.

platform particles by evaluating the influence of the train movement factor on the variation in particle levels. In this study, two aspects are considered to represent the train movement factor: train frequency and train stopping period (or open PSD period). Since the station is a new one, contributions from suspended dust are considered to be negligible. Particle sources that are associated with the train movement factor include train operation (e.g., the wear behaviour of train components) and the passengers loaded and unloaded by the trains. Distinguishing the contribution of these two parts (i.e., the train operation and the passengers) is a challenge due to the complex sources and flow patterns of the particles and the unclear chemical compositions associated with each source. However, a combination of them does give clear insight into the influence of the train movement factor. For example, train frequency is amply demonstrated to have a significant influence on the average $\mathrm{PM}_{10}$ and $\mathrm{PM}_{2.5}$, regardless of the age of the station system (Fig. 5). Although the installation of PSDs has been expected to control air pollutants from the tunnel (Kim et al., 2012), noticeable increases in the mass and number concentrations of coarse particles $(0.3-$ $10 \mu \mathrm{m})$ were observed at the door-side measurement point when the PSDs opened. However, the variation in ultrafine particles (measured with the Nanoscan) did not show similar increases when the PSDs opened. According to scaled laboratory studies on the wear particles emitted from metal parts (Olofsson, 2011; Abbasi et al., 2012; Cha et al., 2016; Liu et al., 2016), those coarse fractions can be traced back to the wear behaviours of train components. At this stage, the amount of measurement data is limited. Further studies are needed to achieve statistically significant results on the trends of the concentrations of the particles.

\section{Comparison with Other Studies}

When comparing the platform particle levels obtained in this study with those found in other studies, it should be kept in mind that great deviations may arise if different measurement instruments are utilized. Results can also vary with different monitoring conditions (e.g., temperature, humidity, season, and the metro systems). For the aerosol monitoring of railway stations in Stockholm (Table 3), the newly built Odenplan railway station has similar levels but slightly lower $\mathrm{PM}_{10}$ levels to those measured at the Odenplan subway station, in spite of different detection methods, while the $\mathrm{PM}_{2.5}$ is lower for the new station. (The new station is below the old subway station.) The lower $\mathrm{PM}_{2.5}$ level may be attributed to the advanced ventilation system on the new station filtering out suspension particles. On the other hand, the difference may be due to the different detectable size ranges of the instrumentation: The OPS can only measure particle sizes greater than $0.3 \mu \mathrm{m}$. For measurements at the same station, Södra, the calibrated OPS in this study presents larger $\mathrm{PM}_{10}$ values than were measured in 2015 (Stockholms läns landsting, 2015).

Great caution is also needed when comparing $\mathrm{PM}_{10}$ and $\mathrm{PM}_{2.5}$ levels worldwide even with the same aerosol monitoring instruments if different calibrations were used. For example, a relatively new underground station (service started in 2011) equipped with PSDs in Seoul was reported to have an average $\mathrm{PM}_{10}$ of around $150 \mu \mathrm{g} \mathrm{m}^{-3}$ and $\mathrm{PM}_{2.5}$ of about $60 \mu \mathrm{g} \mathrm{m}^{-3}$ measured with the OPS 3330 (Kwon et al., 2015). Their OPS result was calibrated by a gravimetric method in the laboratory. These levels are close to the result measured at the Odenplan station in our study (175 and $35 \mu \mathrm{g} \mathrm{m}^{-3}$ for $\mathrm{PM}_{10}$ and $\mathrm{PM}_{2.5}$, respectively). The same optical instrument was used for particle estimation recently 
Table 3. Mean daily levels of $\mathrm{PM}_{10}$ and $\mathrm{PM}_{2.5}$ reported in different railroad stations in Stockholm.

\begin{tabular}{lllll}
\hline Railroad station & $\begin{array}{l}\mathrm{PM}_{10} \\
\left(\mu \mathrm{g} \mathrm{m}^{-3}\right)\end{array}$ & $\begin{array}{l}\mathrm{PM}_{2.5} \\
\left(\mu \mathrm{g} \mathrm{m} \mathrm{m}^{-3}\right)\end{array}$ & Method & Study \\
\hline Odenplan (subway)* & 160 & 60 & PNS 16 T (off-line weight) & (Midander et al., 2012) \\
Odenplan (subway) & 232 & 71 & HI (Harvard impactors) & (Klepczyńska-Nyström et al., 2012) \\
Odenplan (subway) & 232 & 77 & HI & (Klepczyńska Nyström et al., 2010) \\
Odenplan (subway) & 244 & -- & Calibrated Grimm 1.108 & (Fjällström, 2016) \\
Stockholm Central & 25 & -- & TEOM & (Gustafsson et al., 2012) \\
Arlanda Central & 247 & -- & TEOM & (Gustafsson et al., 2012) \\
Arlanda Central & 200 & -- & TEOM & (Gustafsson et al., 2016) \\
Arlanda Central & 155 & 73 & Calibrated Lighthouse & (Silvergren et al., 2017) \\
Arlanda Södra & 88 & -- & TEOM & (Gustafsson et al., 2012) \\
Stockholm Södra & 150 & -- & -- & (Stockholms läns landsting, 2015) \\
Mariatorget (subway) & 470 & 260 & TEOM & (Johansson and Johansson, 2003) \\
Solna (above-ground) & 45 & 8 & Calibrated Lighthouse & This study \\
Stockholm City (new) & 52 & 13 & Calibrated OPS & This study \\
Stockholm Södra & 233 & 41 & Calibrated OPS & This study \\
Odenplan (new)\# & 175 & 35 & Calibrated OPS & This study
\end{tabular}

* Odenplan subway station is a metro station that has been in service since 1952 .

\# Odenplan railway station is a newly built station for commuter trains. It has the same geographic coordinates as the Odenplan subway station but is located deeper than the subway station. It came into use on 10 July 2017.

-- Information is not available.

in the Barcelona metro system (Reche et al., 2017). The number concentrations (of sizes between 0.3 and $10 \mu \mathrm{m}$ ) reported by the authors for a new station equipped with PSDs and advanced ventilation systems (the Llefia station) are about 1.5-2 times those measured in our study (the Odenplan station at P3). The mass concentration at the Llefia station was around $20-40 \mu \mathrm{g} \mathrm{m}^{-3}$ for $\mathrm{PM}_{2.5}$ determined with a DustTrak light-scattering laser photometer (TSI) (Martins et al., 2015a). This result is, however, comparable to the $\mathrm{PM}_{2.5}$ level measured at the Odenplan station in our study $\left(35 \mu \mathrm{g} \mathrm{m}^{-3}\right)$.

More study is required regarding calibrations based on optical, aerodynamic and gravimetric methods that are commonly used for field monitoring to enable a proper and more accurate comparison among different cities worldwide. The default settings of the refractive index for optical instruments correspond to polystyrene latex particles (highly efficient at scattering and completely non-absorbing), which have different optical properties from railway aerosols. Particle size distributions, which depend on the refractive index, can thus be incorrectly estimated with optical instruments. Thus, the optical instruments need to be calibrated correctly for proper calculation of the size distribution and mass concentration. Fridell et al. (2010) used an effective density of $5 \mathrm{~g} \mathrm{~cm}^{-3}$ for railway particles in a tunnel environment to convert the optical diameter measurement (Model 1.108, Grimm) to the $\mathrm{PM}_{10}$ of the aerodynamic diameter. For on-board measurement on a train (Fridell et al., 2011), an effective density of $3.5 \mathrm{~g} \mathrm{~cm}^{-3}$ was determined to obtain the mass concentration from optically counted number concentrations. According to another study at the Arlanda railway station, an effective density of $4 \mathrm{~g} \mathrm{~cm}^{-3}$ was assumed to calibrate the Lighthouse measurements based on the comparison of the Lighthouse to the ELPI measurement (Silvergren et al., 2017). Future studies on the calibration of optical instruments to gravimetric or aerodynamic detection methods for railway aerosol measurement are important for better understanding and more effective control of railway environments. Considering that the particles can vary among stations in terms of their properties, such as chemical compositions and sizes, the use of an average value as the density factor can give deviations to the results. This can influence platform measurements, as in this study, as well as explain the differences between the previously presented studies.

\section{CONCLUSION}

Intensive field measurements of the particle concentrations (PNC, $\mathrm{PM}_{10}$ and $\mathrm{PM}_{2.5}$ ) were conducted at the Odenplan station (a newly built station in Stockholm). The goal was to investigate variations in the platform particulate matter and their potential major factors before and after the station began servicing normal traffic. For comparison, three other stations (Stockholm City, Stockholm Södra and Solna) with differently constructed platforms were monitored simultaneously. The main conclusions from this study may be summarised as follows:

1. The air quality on the new platform was good, with low levels of $\mathrm{PM}_{10}$ and $\mathrm{PM}_{2.5}\left(12\right.$ and $\left.2 \mu \mathrm{g} \mathrm{m}^{-3}\right)$ before it came into service. However, substantial increases in the $\mathrm{PM}_{10}$ and $\mathrm{PM}_{2.5}$ concentrations were noticed after traffic operations started. The average concentrations of the $\mathrm{PM}_{10}$ and $\mathrm{PM}_{2.5}$ increased to 120 and $30 \mu \mathrm{g} \mathrm{m}^{-3}$ after the station had been operating for 1 week. These concentrations further increased, to 175 and $35 \mu \mathrm{g} \mathrm{m}^{-3}$, after it had been in operation for 3 months.

2. A strong influence from train movement (train frequency and train stopping time) on the particle levels was observed. Increasing trends for $\mathrm{PM}_{10}$ and $\mathrm{PM}_{2.5}$ were 
noticed as the train frequency increased. When trains stopped at the station and the PSDs opened, noticeable increases in the mass and number concentrations of coarse particles $(0.3-10 \mu \mathrm{m})$ were measured near the door. The influence of the doors opening on particle concentrations measured in the middle of the platform was not significant.

3. At the Odenplan station, the platform particulate concentrations were comparable to those measured at the Södra station when the traffic frequency was similar, despite the fact that the former is a newly built station, whereas the latter is an old one. Reduced particle levels were observed for the other newly opened station (Stockholm City), which had less traffic.

\section{ACKNOWLEDGEMENTS}

The authors wish to thank Mr. Edwin Bergstedt, Mr. Peter Carlsson and Mr. Yezhe Lyu from KTH Royal Institute of Technology, Mr. Michael Norman and Ms. Jennie Hurkmans from SLB-analys; Mr. Martin Lundblad and Mr. Dan Eld from Blueair for their great contributions and technical assistance in the field test. We greatly appreciate the technical support of Mr. Mohammad Mohseni from MTR and Mr. Jan Andersson from SL. We also thank Peter Ahlvik from ExIS for his technical assistance in the post-analysis of the measurement data. Last, but not least, the main author would like to thank Dr. Hailong Liu for his support.

\section{SUPPLEMENTARY MATERIAL}

Supplementary data associated with this article can be found in the online version at http://www.aaqr.org.

\section{REFERENCES}

Abbasi, S., Jansson, A., Olander, L., Olofsson, U. and Sellgren, U. (2012). A pin-on-disc study of the rate of airborne wear particle emissions from railway braking materials. Wear 284-285: 18-29.

Branǐ, M. (2006). The contribution of ambient sources to particulate pollution in spaces and trains of the Prague underground transport system. Atmos. Environ. 40: 348356.

Cartenì, A., Cascetta, F. and Campana, S. (2015). Underground and ground-level particulate matter concentrations in an Italian metro system. Atmos. Environ. 101: 328-337.

Cha, Y., Hedberg, Y., Mei, N. and Olofsson, U. (2016). Airborne wear particles generated from conductor rail and collector shoe contact: Influence of sliding velocity and particle size. Tribol. Lett. 64: 40.

Cha, Y. and Olofsson, U. (2018). Effective density of airborne particles in a railway tunnel. Aerosol Sci. Technol. 52: 886-899.

Cha, Y., Olofsson, U., Gustafsson, M. and Johansson, C. (2018). On particulate emissions from moving trains in a tunnel environment. Transp. Res. Part D 59: 35-45.
Cheng, Y.H., Lin, Y.L. and Liu, C.C. (2008). Levels of $\mathrm{PM}_{10}$ and $\mathrm{PM}_{2.5}$ in Taipei Rapid Transit System. Atmos. Environ. 42: 7242-7249.

Fjällström, P. (2016). Mätning av partikelhalter i tunnelbanan - Underlag till MKB för nya sträckningar. Del 1. Stockholm.

Fridell, E., Ferm, M. and Ekberg, A. (2010). Emissions of particulate matters from railways - Emission factors and condition monitoring. Transp. Res. Part D 15: 240-245.

Fridell, E., Björk, A., Ferm, M. and Ekberg, A. (2011). On-board measurements of particulate matter emissions from a passenger train. Proc. Inst. Mech. Eng. Part F 225: 99-106.

Gustafsson, M., Abbasi, S., Blomqvist, G., Cha, Y., Gudmundsson, A., Janhäll, S., Johansson, C., Norman, M. and Olofsson, U. (2016). Particles in road and railroad tunnel air: Sources, properties and abatement measures. Swedish National Road and Transport Research Institute (VTI), Sweden.

Gustafsson, M., Blomqvist, G., Swietlicki, E., Dahl, A. and Gudmundsson, A. (2012). Inhalable railroad particles at ground level and subterranean stations - Physical and chemical properties and relation to train traffic. Transp. Res. Part D 17: 277-285.

Johansson, C. and Johansson, P.Å. (2003). Particulate matter in the underground of Stockholm. Atmos. Environ. 37: 3-9.

Kang, S., Hwang, H., Park, Y., Kim, H. and Ro, C.U. (2008). Chemical compositions of subway particles in Seoul, Korea determined by a quantitative single particle analysis. Environ. Sci. Technol. 42: 9051-9057.

Kim, K.Y., Kim, Y.S., Roh, Y.M., Lee, C.M. and Kim, C.N. (2008). Spatial distribution of particulate matter $\left(\mathrm{PM}_{10}\right.$ and $\left.\mathrm{PM}_{2.5}\right)$ in Seoul Metropolitan Subway stations. J. Hazard. Mater. 154: 440-443.

Kim, K.H., Ho, D.X., Jeon, J.S. and Kim, J.C. (2012). A noticeable shift in particulate matter levels after platform screen door installation in a Korean subway station. Atmos. Environ. 49: 219-223.

Klepczyńska Nyström, A, Svartengren, M., Grunewald, J., Pousette, C., Rödin, I., Lundin, A, Sköld, C.M., Eklund, A. and Larsson, B.M. (2010). Health effects of a subway environment in healthy volunteers. Eur. Respir. J. 36: 240-248.

Klepczyńska-Nyström, A., Larsson, B.M., Grunewald, J., Pousette, C., Lundin, A., Eklund, A. and Svartengren, M. (2012). Health effects of a subway environment in mild asthmatic volunteers. Respir. Med. 106: 25-33.

Kwon, S.B., Jeong, W., Park, D., Kim, K.T. and Cho, K.H. (2015). A multivariate study for characterizing particulate matter $\left(\mathrm{PM}_{10}, \mathrm{PM}_{2.5}\right.$, and $\left.\mathrm{PM}_{1}\right)$ in Seoul metropolitan subway stations, Korea. J. Hazard. Mater. 297: 295-303.

Liu, H., Cha, Y., Olofsson, U., Jonsson, L.T.I. and Jönsson, P.G. (2016). Effect of the sliding velocity on the size and amount of airborne wear particles generated from dry sliding wheel-rail contacts. Tribol. Lett. 63: 30.

Martins, V., Cruz Minguillón, M., Moreno, T., Querol, X., de Miguel, E., Capdevila, M., Centelles, S. and Lazaridis, M. (2015a). Deposition of aerosol particles from a 
subway microenvironment in the human respiratory tract. J. Aerosol Sci. 90: 103-113.

Martins, V., Moreno, T., Minguillón, M.C., Amato, F., de Miguel, E., Capdevila, M. and Querol, X. (2015b). Exposure to airborne particulate matter in the subway system. Sci. Total Environ. 511: 711-722.

Martins, V., Moreno, T., Mendes, L., Eleftheriadis, K., Diapouli, E., Alves, C.A., Duarte, M., de Miguel, E., Capdevila, M., Querol, X. and Minguillón, M.C. (2016). Factors controlling air quality in different European subway systems. Environ. Res. 146: 35-46.

Midander, K., Elihn, K., Wallén, A., Belova, L., Karlsson, A.K.B. and Wallinder, I.O. (2012). Characterisation of nano- and micron-sized airborne and collected subway particles, a multi-analytical approach. Sci. Total Environ. 427-428: 390-400.

Moreno, T., Reche, C., Minguillón, M.C., Capdevila, M., de Miguel, E. and Querol, X. (2017). The effect of ventilation protocols on airborne particulate matter in subway systems. Sci. Total Environ. 584-585: 13171323.

Mugica-Álvarez, V., Figueroa-Lara, J., Romero-Romo, M., Sepúlvea-Sánchez, J. and López-Moreno, T. (2012). Concentrations and properties of airborne particles in the Mexico City subway system. Atmos. Environ. 49: 284-293.

Olofsson, U. (2011). A study of airborne wear particles generated from the train traffic-Block braking simulation in a pin-on-disc machine. Wear 271: 86-91.

Querol, X., Moreno, T., Karanasiou, A., Reche, C., Alastuey, A., Viana, M., Font, O., Gil, J., de Miguel, E. and Capdevila, M. (2012). Variability of levels and composition of $\mathrm{PM}_{10}$ and $\mathrm{PM}_{2.5}$ in the Barcelona metro system. Atmos. Chem. Phys. 12: 5055-5076.

Reche, C., Moreno, T., Martins, V., Minguillón, M.C., Jones, T., de Miguel, E., Capdevila, M., Centelles, S. and Querol, X. (2017). Factors controlling particle number concentration and size at metro stations. Atmos. Environ. 156: 169-181.

Salma, I., Weidinger, T. and Maenhaut, W. (2007). Timeresolved mass concentration, composition and sources of aerosol particles in a metropolitan underground railway station. Atmos. Environ. 41: 8391-8405.

Seaton, A, Cherrie, J., Dennekamp, M., Donaldson, K., Hurley, J.F. and Tran, C.L. (2005). The London Underground: Dust and hazards to health. Occup. Environ. Med. 62: 355-362.

Silvergren, S., Olofsson, U., Andersson, M., Lyu, Y. and Norman, M. (2017). Ombordmätningar av partiklar och koldioxid i X60B förarhytter.

Stockholms läns landsting (2015). Åtgärder för luftkvalitet - Underlag till MKB för järnvägsplan.

Sundh, J. and Olofsson, U. (2011). Relating contact temperature and wear transitions in a wheel-rail contact. Wear 271: 78-85.

Telliskivi, T. and Olofsson, U. (2001). Contact mechanics analysis of measured wheel-rail profiles using the finite element method. Proc. Inst. Mech. Eng. Part F 215: 6572 .

Received for review, June 19, 2018

Revised, October 82018

Accepted, October 9, 2018 